\title{
Doping nikel (Ni) metal in zeolitic imidazolate framework-8 using green synthesis method
}

\author{
Rahmatul Fajri ${ }^{*}$, Puji Wahyuningsih ${ }^{1}$, Jofrishal Jofrishal ${ }^{2}$, and Ratna Ediati $^{3}$ \\ ${ }^{1}$ Department of Chemistry, Faculty of Engineering, Universitas Samudra, Jl. Meurandeh Langsa Aceh 24416, Indonesia \\ ${ }^{2}$ Department of Chemistry Education, Faculty of Teacher Training and Education, Universitas Samudra, Jl. Meurandeh Langsa Aceh \\ 24416, Indonesia \\ ${ }^{3}$ Department of Chemistry, Faculty of Mathematics and Natural Sciences Institute of Technology of Sepuluh Nopember (ITS), Jl. \\ Arif Rahman Hakim, Surabaya 60111 Indonesia
}

\begin{abstract}
Ni-Doping Ni metal into ZIF-8 material aims to increase the ability of ZIF-8. Ni-ZIF-8 was synthesized using an environmentally friendly method by reusing methanol as a solvent in the previous process and carried out at room temperature. The ratio of the molar ratios used was 1:4:4 for Zinc nitrate:2methylimidazolate: TEA. As an effort to save the environment from the dangers of waste caused by the filtrate, Ni-ZIF-8 was then synthesized using the same filtrate up to six times. Based on the results of characterization using XRD, FTIR and SEM showed that the Ni-ZIF-8 material synthesized using the filtrate had similarities with Ni-ZIF-8 synthesized with pure methanol.
\end{abstract}

\section{Introduction}

Zeolitic Imidazole framework (ZIF-8) is a material synthesized from zinc metal and imidazole ligands with frameworks that are similar to zeolite. [1]. ZIF-8 has many advantages in various fields, such as gas storage materials, adsorbents, and catalysts [2-5]. Synthesis of ZIF-8 can be carried out using several organic solvents such as methanol, DMF, and mixing between the two solvents [6-7]. The addition of other metals such as $\mathrm{Ni}$, $\mathrm{Co}$, and $\mathrm{Fe}$ in the synthesis process of ZIF- 8 aims to improve the performance of ZIF-8 that's expected it has better performance than before metal addition. For example, the use of Fe metal in the synthesis of ZIF-8 as an adsorbent has been successfully applied to remazol Deep Black RGB pollutants found in water. The results of this study indicate that Fe-ZIF- 8 has a better capacity compared to ZIF-8. [8-10].

The excessive use of organic solvents in the synthesis of inorganic materials creates new problems for the environment, that are the waste from the filtrate produced by the synthesis pollutes the environment. One of the efforts made by researchers is to minimize the use of organic solvents in the synthesis, by recycling the remaining solvent from the previous synthesis [11].

\section{Method}

\subsection{Procedures}

$\mathrm{Zn}\left(\mathrm{NO}_{3}\right)_{2} .4 \mathrm{H}_{2} \mathrm{O}$ and $\mathrm{NiCl}_{2} .6 \mathrm{H}_{2} \mathrm{O}(5 \%)$ dissolved in methanol. In another place, using methanol, triethylamine and 2-methyl imidazole were dissolved.
The two solutions were mixed in one place and then stirred for 1 hour at room temperature. Furthermore, the residue obtained was filtered and washed using pure methanol. The sample was dried for 3 hours at $60^{\circ} \mathrm{C}$, and again dried for 2 hours at $100^{\circ} \mathrm{C}$ to remove the TEA present in the sample. The obtained material is labeled P1-Ni-ZIF-8.

Ni-ZIF-8 was then synthesized with solvent from the P1-Ni-ZIF-8 synthesis filtrate. All treatments were carried out the same as before. The obtained material was then labeled P2-Ni-ZIF-8. Synthesis was carried out up to 6 times.

\subsection{Characterization of Synthesized Materials}

The XRD characterization aims to determine the structure of the resulting solid and compare it to the simulated ZIF-8 diffractogram. The Ni-ZIF-8 material was analyzed using XRD by 1 gram of the crushed sample and placing it in the holder provided. The sample was irradiated with an X-ray with a $\mathrm{Cu} \mathrm{K} \alpha$ axis $(1=$ $1.5405)$ at $40 \mathrm{kV}$ and $30 \mathrm{~mA}$, at $2 \theta$ from $2^{\circ}-50^{\circ}$ with a scan speed of $0.05^{\circ} / \mathrm{sec}$. The data obtained are in the form of $2 \theta, d$ spacing and intensity of diffraction peaks. Then, the data obtained were compared with references [12]. Characterization with FTIR was used to determine the peak or absorption characteristics of the Ni-ZIF-8 material. FTIR characterization was carried out on solids ZIF-8, P1-Ni-ZIF-8 and P3-Ni-ZIF-8, and recorded at wavenumbers $400-4000 \mathrm{~cm}-1$. The samples were also characterized by scanning electron microscopy (SEM) $(20 \mathrm{kV}$ and $9.5 \mathrm{~mm})$.

\footnotetext{
* Corresponding author: rahmatulfajri@unsam.ac.id
} 


\section{Results And Discussion}

\subsection{Characterization of Zeolitic Imidazole Frameworks-8 Doping Nickel (Ni-ZIF-8)}

\subsubsection{X-Ray Difraction Analysis}

The synthesis of Ni-ZIF- 8 begins with the dissolution of $\mathrm{Zn}\left(\mathrm{NO}_{3}\right)_{2} \cdot 4 \mathrm{H}_{2} \mathrm{O}$ and $\mathrm{NiCl}_{2} \cdot 6 \mathrm{H}_{2} \mathrm{O}$ in methanol, producing a colorless solution (solution $\mathrm{A}$ ). then the methylimidazole ligand and TEA were dissolved in methanol solvent, producing a colorless solution (solution B). Next, the two solutions are mixed in a closed vial and stirred for 1 hour. When the two solutions are mixed, the color changes from a colorless solution to a purplish blue. The color change that occurs is a possibility of competition between $\mathrm{Zn}^{2+}$ and $\mathrm{Ni}^{2+}$ in their interaction with methylimidazole ligands and forming a precipitate. After the mixture was allowed to stand for 24 hours, two layers were formed. The bottom layer is a purplish-blue precipitate, and the top layer is a clear greenish liquid. The separation of the two layers is carried out by filtering. After drying, the solid is obtained in the form of a purplish blue powder given the notation P1-Ni-ZIF-8. The resulting filtrate was used for the subsequent synthesis of Ni-ZIF-8. The purplish blue color seen in the resulting solid is due to the addition of the transition metal $\mathrm{Ni}$ which tends to form colored compounds or complex ions. This is related to the excitation of electrons that occurs in the $d$ subshell. An electron jumps from a lower energy $d$ orbital to a higher energy d orbital resulting in an excited electron. The difference in energy of the excited electron is equal to the energy of the absorbed photon, thus showing color at a wavelength that has the same energy as the energy of the excited atom (crystal field theory) [13].

The XRD pattern of Ni-ZIF-8 (Fig. 1). The pattern compare with the simulated pattern of ZIF-8 Gross et. al [14]. P1-Ni-ZIF-8 solid diffractogram synthesized using pure solvent has a higher intensity than the solid synthesized using filtrate. This is occur due to the amount of pure solvent used is more than the solvent from the filtrate. Characteristic peaks of Ni-ZIF-8 were synthesized using filtratte from previous synthesis are the same. Based on Gross et. at [14] difraction pattern $\mathrm{X}$-Ray has characteristic peaks. There was sliding slightly peaks between ZIF-8 and Ni-ZIF-8. The sliding effect indicate $\mathrm{Ni}^{2+}$ has been dopped in ZIF-8, for replacing most between $\mathrm{Zn}$ metal with Ni metal. The metal replace between $\mathrm{Zn}$ metal with Ni metal doesn't change of ZIF-8 scructure formed. As well Ni-ZIF-8 has been synthesized using filtrate from frevios synthesis, it capable produce the same sctructure with the first synthesis of Ni-ZIF-8. Repetition of Ni-ZIF-8 synthesis using filtrate from previos synthesis can be done six times.

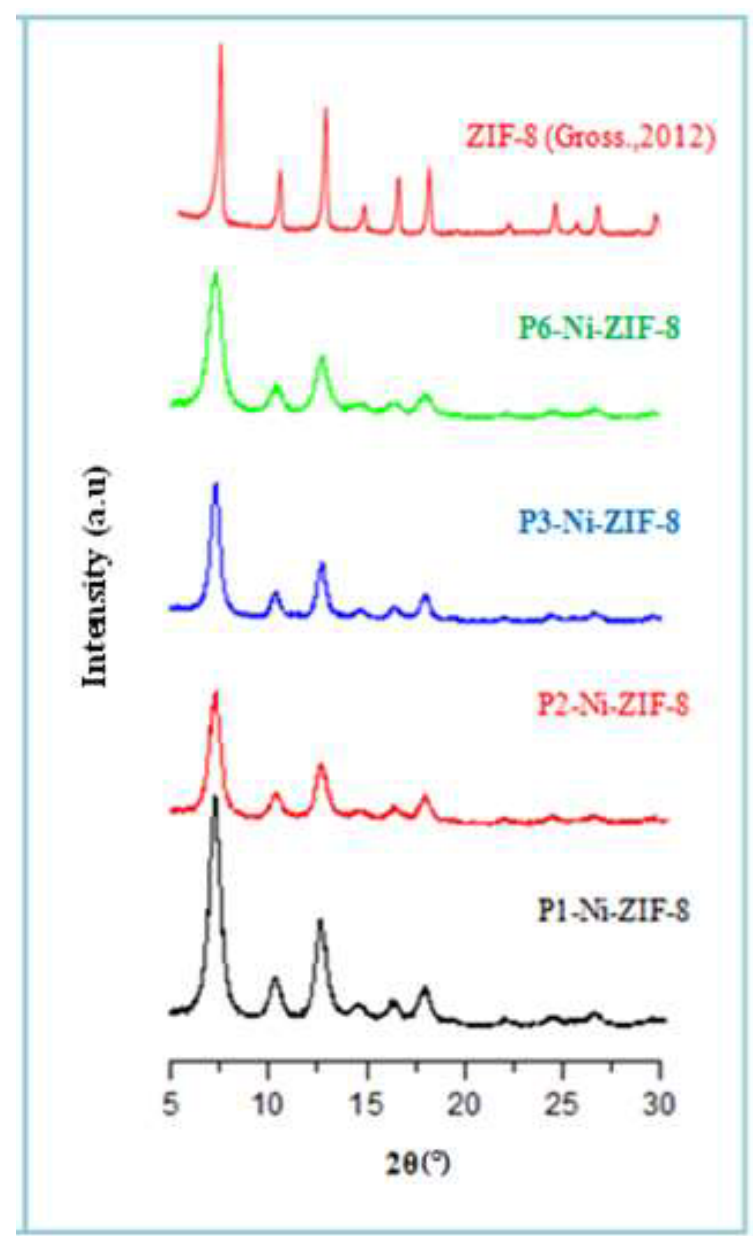

Fig. 1. X-ray diffraction pattern of the sample ZIF-8 and Ni-ZIF-8 synthesized and research Gross et al. (2012).

\subsubsection{Spektrofotometer Fourier Transform Infra- Red Analysis}

The FTIR spectra of the obtained Ni-ZIF-8 materials (Fig. 2) confirm that the chemical bond structure corresponds to that reported for ZIF-8 [15]. Figure 2 shows 2-methylimidazole has a strong and broadband at wave number 3400 to $2200 \mathrm{~cm}^{-1}$. The confirm vibrations of the Hydrogen bond established between the Nitrogen group which has a hydrogen bond. This indicates that 2methylimidazole has been deprotonated. FTIR of NiZIF-8 shows the formation of a bond Zink between Nickel-metal the presence of an absorption band at a wavelength of $421 \mathrm{~cm}^{-1}$, and the presence of vibrations from carbon-hydrogen bonds at wavenumber $760 \mathrm{~cm}^{-1}$ [16]. Furthermore, there is an absorption band at a wavenumber of $1586 \mathrm{~cm}^{-1}$ with a weak intensity which is a bending vibration of Carbon and Nitrogen. 


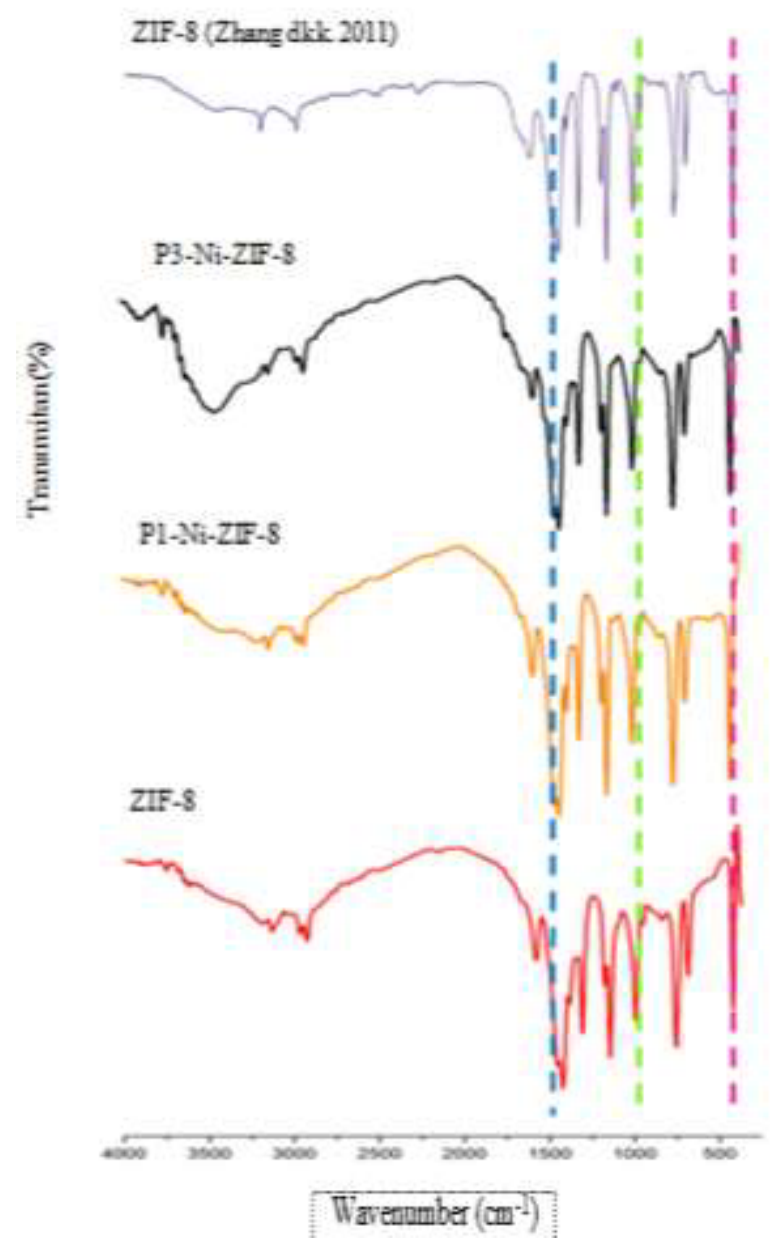

Fig. 2. FTIR spectra of ZIF-8 and Ni-ZIF-8 reported Zhang et al. 2011

Based on FTIR is known that all samples synthesized and reuse have a characteristic absorption band of material ZIF-8 and there was a slight shift as well as a decrease in the peak intensity at several wave numbers due to the addition of $\mathrm{Ni}^{2+}$ cations in the synthesis process.

\subsubsection{Scanning Electron Microscopy Analysis}

SEM image (Fig. 3) showed that they were aggregated as globular particles of Ni-ZIF-8 material. The material of Ni-ZIF-8 has a microsize and an imperfect cube shape and some are round [5]. The SEM results of the P6-Ni-ZIF-8 material show a variety of surface morphology, some are box-shaped, some are slightly rectangular and some are even irregular. P1-NiZIF-8 has imperfect cube morphology and confirm about particle size smaller than ZIF-8. The particle size of P1-Ni-ZIF-8 is $\pm 22.66 \mathrm{~m}$ while that of ZIF- 8 is \pm 46 m. Fig. 4(b) and 4(c) shows the P3-Ni-ZIF-8 and P6-NiZIF-8 morphology respectively. Both P3-Ni-ZIF-8 and P6-Ni-ZIF-8 have cube morphology and particle size around $46.2583 .3 \mathrm{~m}$. This result shows the possibility of synthesis Ni-ZIF-8 using filtrate or we call green method.

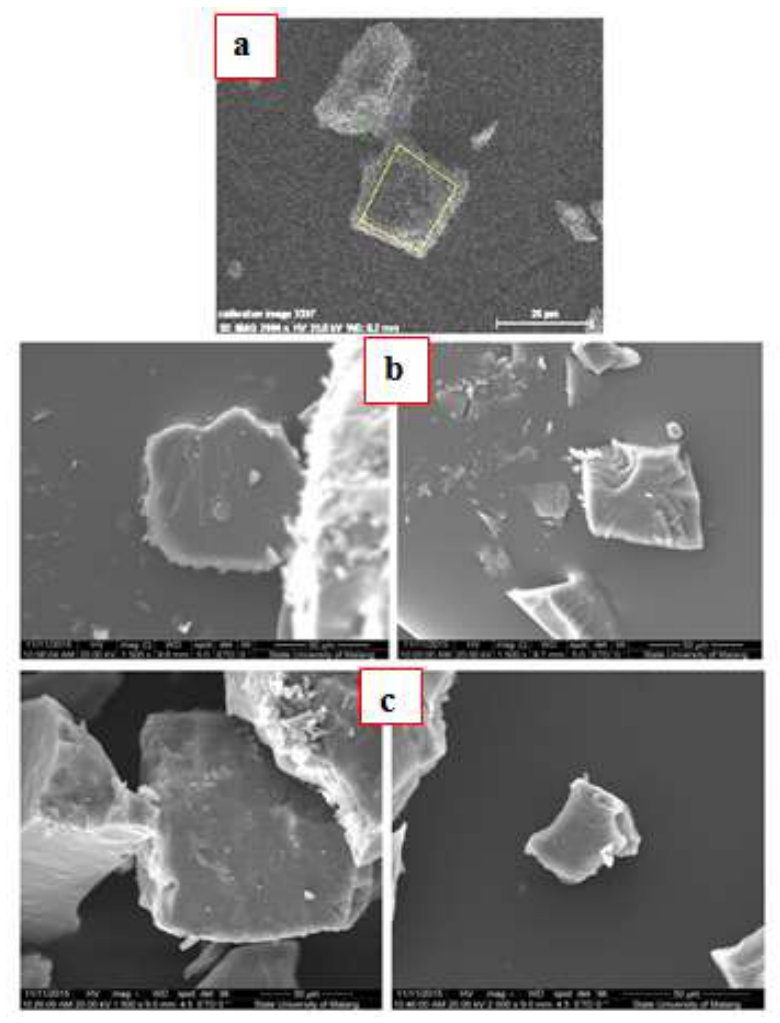

Fig. 3. SEM image of (a) P1-Ni-ZIF-8, (b) P3-Ni-ZIF-8 and (c) P6-Ni-ZIF-8

\section{Conclusions}

Ni-ZIF-8 material has been successfully synthesized using an environmentally friendly method, with the addition of TEA as a deprotonating agent, and synthesized at room temperature. Based on the results of the analysis using XRD, FTIR and SEM showed that there was no change in the structure of the resulting NiZIF-8. This synthesis method can be applied as an effort to anticipate environmental damage from the waste generated from the synthesis.

Acknowledgments. This research was funded by Universitas Samudra through the Institute for Research and Community Service (LPPM) for a research grant Penelitian Dasar Unggulan (PDU). We would like to express our gratitude to several institutions, including the Basic Laboratory of Universitas Samudra, Lhokseumawe Polytechnic Laboratory, and the Chemistry Laboratory of Universitas Syiah Kuala.

\section{References}

1. Q. Bao., Y. lou., T. Xiang., J. Chen, Inorganic Chemistry Communication 37, 170-173 (2013)

2. K. S. Park., Z. Ni., A.P. Cote., J.Y. Choi., R. Huang., F. J. U. Romo., H.K. Chae., M. O'Keeffe., O. M. Yaghi. PNAS 103. 10187-10191(2006)

3. B. Chen., F. Bai., Y.Zhu., Y. Xia. Microporous and Mesoporous Material 193. 7-14 (2014)

4. Y. Pan., Y. Liu., G. Zeng, L. Zhao., Z. Lai. Chem. Commun. 47. 2017-2073 (2011)

5. L.T.L. Nguyen., K.K.A. Le., N.T.S. Phan. 33. 688698 (2012) 
6. Y. H. Hu., L. Zhang. Adv. Mater. 22. E117-E130 (2010)

7. E.I. Bustamante., J.I. Fernandez., J. M. Zamaro. Journal of Colloid and Interface Science. 424. 3743 (2014)

8. J. M. Yang., Q. Liu., W. Y. Sun, Microporous and Mesoporous Material 190, 26-31 (2014)

9. J. A. Botas., G. Calleja., M. Sanchez., M. G. Orcajo. Hydrogen Energy 36, 10834-10844 (2011)

10. M. T. Thanh., T. V. Thien., V. T. Chau., P. D. Du., N. P. Hung., D. Q. Khieu Hindawi Journal of Chemistry. 1-18 (2017)

11. N.K. Demir., B. Topuz., L. Yilmaz., H. Kalipcilar. Microporous and Mesoporous Material. 198, 291300 (2014)

12. Elements of X-ray diffraction, second Ed., B.D. Cullity Ed., USA, 1978.

13. Adlim, Kimia Anorganik. Universitas Syiah Kuala. Banda Aceh. (2009)

14. A.F. Gross., E. Sherman., J.J. Vajo. Dalton Trans. 41, 5458-5460 (2012)

15. Z. Zhang., S. Xian., H. Xi., H. Wang., Z. Li. Chemical Engineering Science. 66, 4878-4888.

16. R. M. Silverstein., F. X. Webster., D. J. Kiemle, Spectrometric Identification of Organic Compounds. 7th Ed., John Wiley and Sons, Inc., New York. (2005). 